\title{
BILATERAL SUNCT SYNDROME ASSOCIATED TO CHRONIC MAXILLARY SINUS DISEASE
}

\author{
Denis Bernardi Bichuetti', Wellington Yugo Yamaoka², \\ João Ricardo Parrela Bastos ${ }^{3}$, Deusvenir de Souza Carvalho ${ }^{4}$
}

\begin{abstract}
SUNCT syndrome (short lasting unilateral neuralgiform headache with conjuntival injection and tearing) is defined as short attacks of periorbital unilateral pain and accompanied by ipsilateral lacrimation and redness of the same eye. We present an unusual SUNCT case with bilateral pain that started five years ago after an acute maxillary sinus infection that evolved to chronic sinusitis. This association has been described in few SUNCT cases, but its causal role remains uncertain. The patient was a 58 years old man that fulfilled a headache diary that showed the usual circadian pattern, worsening in the morning and afternoon, and responded to treatment with gabapentina. He was submitted to a functional endoscopic sinus surg e ry and evolved with milder pain. In a review of 21 patients, 5 had a past medical history of sinusitis, but the causal role of this association remained uncertain.
\end{abstract}

KEY WORDS: SUNCT, bilateral, sinusitis, gabapentina

\begin{abstract}
Síndrome SUNCT de ocorrência bilateral associada a sinusopatia maxilar crônica
RESUMO - A síndrome SUNCT (short lasting unilateral neuralgiform headache with conjuntival injection and tearing) é definida como curtos ataques de dor periorbital unilateral, acompanhada de lacrimejamento e h i p e remia conjuntival ipsilateral. Apresentamos um raro caso de SUNCT com dor bilateral com evolução de cinco anos e iniciado após uma infecção de seio maxilar que evoluiu para sinusite crônica. Esta associação foi descrita em poucos casos de SUNCT, porém pouco esclarecida. O paciente era um homem de 58 anos que p reencheu um diário de dor que demonstrou o típico padrão circadiano da síndrome, com pioras matinais e vespertinas, e apresentou melhora com uso de gabapentina. Submetido a ciru rgia endoscópica funcional em seio maxilar e evoluiu com modulação da dor, sugerindo um potencial efeito benéfico após tratamento da sinusopatia.Na revisão de literatura encontramos 21 casos de SUNCT bilateral, cinco dos quais apresentavam história de sinusite; no entanto, a relação entre as duas entidades permanece ainda incerta.
\end{abstract}

PALAVRAS-CHAVE: SUNCT, bilateral, sinusite, gabapentina.

SUNCT syndrome (short lasting unilateral neuralgiform headache with conjuntival injection and tearing) was first described in 1989 and is defined as short attacks of periorbital unilateral pain and accompanied by ipsilateral lacrimation and redness of the same eye (Table 1) ${ }^{1}$. Since its first reports it has been seldom associated with underlying diseases, when it is usually associated with symptoms others than the ones cited in the criteria of International Headache Society Classification ${ }^{2-5}$. In a review of 21 patients, 5 had a past medical history of sinusitis, but the causal role of this association remained uncertain ${ }^{1,6-9}$. In rare exceptions the pain might be bilateral. Symptoms have been occasionally relieved with the use of gabapentin, topiramate and lamotrigine ${ }^{10-19}$.

\section{CASE}

We report on a 58-year-old non white male with a past medical history of bilateral lachrymal duct surgeries and trauma in the left forehead in his infancy, who suffered from periorbital stabbing eye pain lasting 5 to 10 seconds accompanied by conjuntival injection and tearing. The attacks started five years ago after he had an acute maxillary sinus infection presenting with proptosis and lateral deviation of the left eye due to fronto-ethmoidal mucocele, diagnosed by CT scan, requiring surgical drainage of the paranasal sinuses. After this intervention he developed chronic sinusitis, confirmed with CT and MRI scans (Fig 1). A few weeks after the procedurehe evolved stabbing eye pain described as "a needle sticking into my eye", lasting 5 to 10 seconds, accompanied by conjuntival injection and tearing, that could be triggered by cold weather and forceful reading. Although he w as not able to count, he re fe rred

Escola Paulista de Medicina (EPM) - Federal University of São Paulo (UNIFESP), São Paulo SP, Brazil - Department of Neurology and Neurosurgery - ENT Department: ' Residente em Neurologia; ${ }^{2}$ Pós Graduando em Otorrinolaringologia; ${ }^{3}$ Residente em Otorrinolaringologia; ${ }^{4}$ Chefe do Setor de Investigação e Tratamento de Cefaléias.

Received 6 September 2005, received in final form 1 December 2006. Accepted 1 February 2006.

Dr. Denis Bernardi Bichuetti - Rua Luiz Dib Zogaib 80 - 05613-020 São Paulo SP - Brasil. E-mail: denisbichuetti@globo.com 
Table 1. SUNCT Criteria
A. At least 20 attacks fulfilling criteria B-d:
B. Attacks of orbital, supraorbital or temporal stabbing or pulsating pain lasting 5 - 240 seconds.
C. Pain is accompanied by ipsilateral conjuntival injection and tearing.
D. Attacks occur with a frequency from 5 to 300 per day.
E. Not attributed to another disorder.
The international Classification of Headache diseases, $2^{\text {nd }}$ ed. (Cephalalgia 2004;24:suppl 1).

the attacks occurred most frequently in the left eye, occasionally in the right eye and seldom bilateral. He denied nausea, vomiting or any sensitivity to light, sounds or scents. He was instructed to fulfill a headache diary that revealed these attacks in a circadian pattern, worsening in the morning and afternoon (Graphic 1). He re ported no pain between attacks.

B e fo re he attended our clinic he was submitted to diverse drug regimens, including carbamazepine, amitryptiline, codeine, tramadol and indomethacin, without relief. He was stared on augmentation doses of gabapentin and evolved with ameliorating of pain attacks and almost complete resolution with $1800 \mathrm{mg} /$ daily (Graphic 2), keeping the characteristic circadian pattern.

With the hypothesis that his chronic sinusitis might be generating the attacks, he was submitted to a functional endoscopic sinus surgery (FESS), with removal of great amount of purulent material from his left maxillary sinuses. After surgery he reported change in pain characteristics from paroxysmal stabbing to continuous bifrontal pain, assuming a tightness pattern. All the more we could note that he retumed to work and that attacks of pain and re dness of the eye were no more observed during clinical appointments, suggesting that the pain was modulated to a milder pattern.

\section{DISCUSSION}

This patient presented with frequent eye pain at-

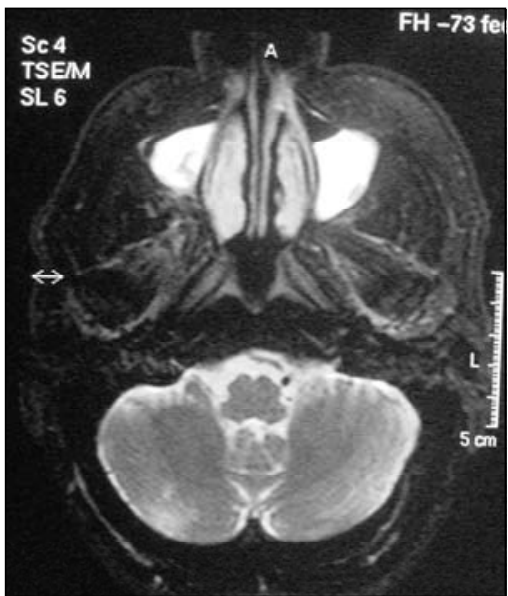

Fig 1. T2 weighted MRI on 5 years after the symptoms start ed. Note the hyper intense material fill ing both maxillary sinuses.

tacks that fulfill criteria for possible SUNCT syndrome, as the pain was occasionally bilateral ${ }^{20}$. All the more, his ability in fulfilling the headache diary has contributed to the characterization of attacks frequency and periodicity. The existence of a circadian rhythm in SUNCT, with worsening in the morning and afternoon, has been reported and is supposed to be related to hypothalamus activation during pain attacks ${ }^{21-23}$.

The treatment of SUNCT pain is, as demonstrated by this case, hard to achieve. Reports on the use of topiramate, lamotrigine and gabapentin have shown to ameliorate or fully relief patients from attacks ${ }^{10-19}$. We could not find any randomized control trial comparing these drugs, the choice for gabapentina was own to its ease of access from the patient, rapid titration and adverse effects profile 24,25 .

Although our patient has reported little relief, the change in pain characteristics and the fact that he has ret u rned to work suggests that FESS and sinus drai-

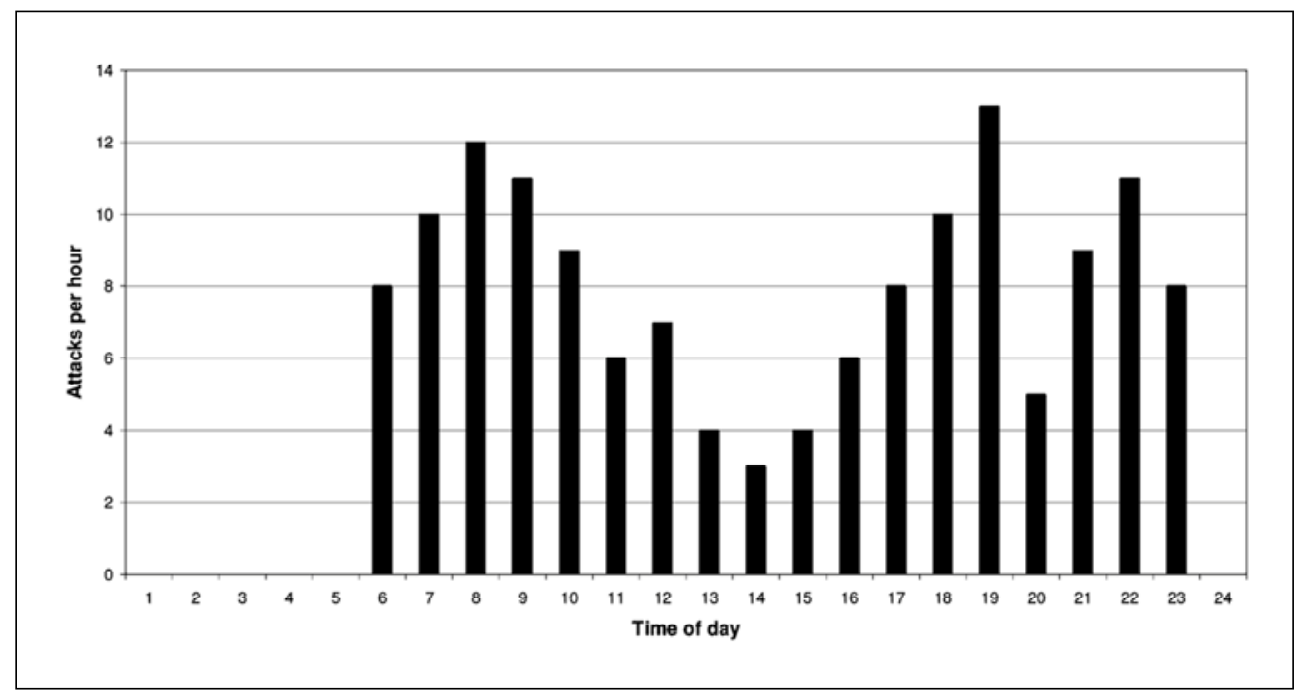

Graphic 1. Number of at tacks per hour in one day. 


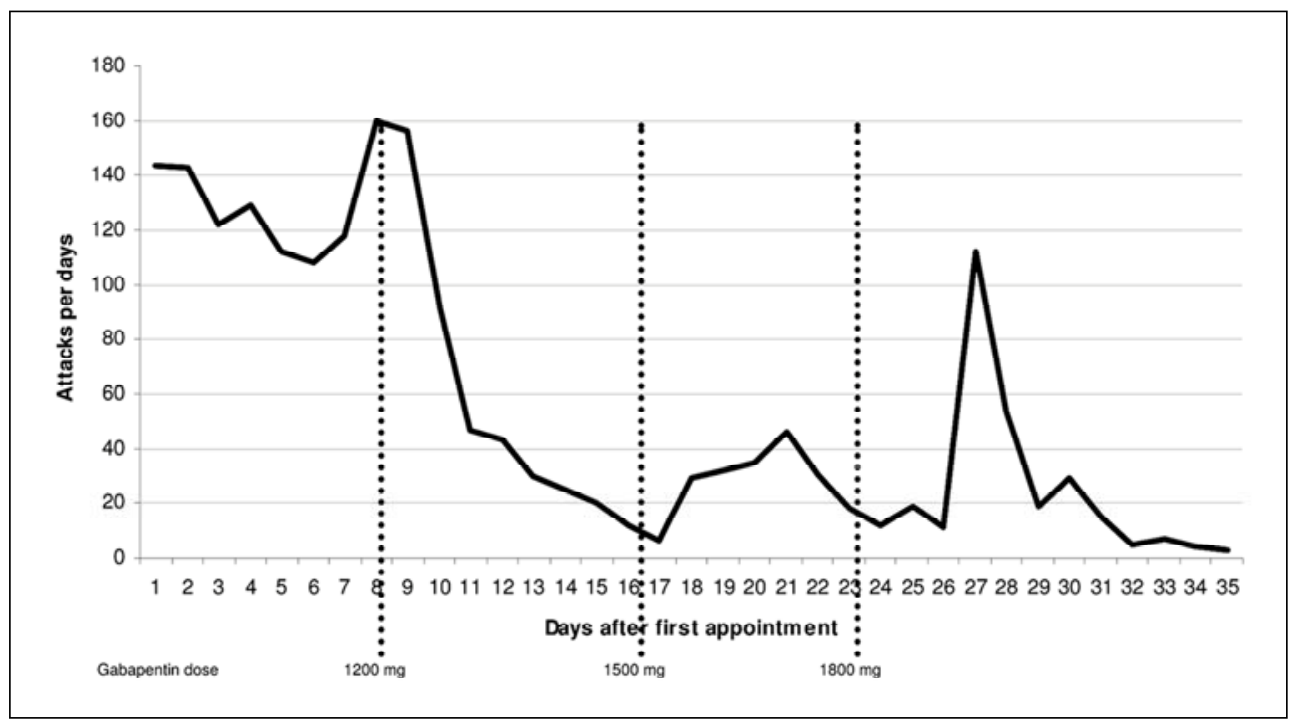

Graphic 2. Number of attacks per day after treatment with gabapentin. The peak num ber of attacks/ day from day 26 to 30 was attributed to weather changes. nage could have ameliorated the attacks. Based on this sole report it is difficult to establish a connection between SUNCT syndrome and sinus disease, though we hypothesize that the proximity of craniofacial structures and trigeminal nerve endings might be related in precipitating attacks, as also thought on a report of SUNCT attacks triggered by forceful mouth opening $^{26}$. It is speculative that the interventions for treating lachrymal duct disease and head trauma might have caused irritative lesions on nerve term inals in craniofacial structures, but the association to SUNCT attacks remains uncertain as they took place more than 40 years before the development of pain.

In conclusions, SUNCT syndrome remains an infrequent condition, yet an underlying disease must always be excluded. We have demonstrated that the relief from chronic sinus disease can exert influence on SUNCT paroxysmal pain attacks, suggesting that the proximity of craniofacial structures might be related to this syndrome's genesis. Medical treatment should be attempted with topiramate, lamotrigine and gabapentin, or if present, removal of the precipitating factor.

\section{REFERENCES}

1. Sjaastad O, Saunte C, Salvesen $R$, et al. Shortlasting unilateral neuralgiform headache attacks with conjunctival injection, tearing, sweating, and rhinorrhea. Cephalalgia 1989;9:147-156.

2. Bussone G, Leone M, Dalla Volta G, Strada L, Gasparotti R, Di Monda V. Short-lasting unilateral neuralgiform headache attacks with tearing and conjunctival injection: the first "symptomatic" case? Cephalalgia 1991;11:123-127.

3. Morales F, Mostacero E, Marta J, Sanchez S. Vascular malformation of the cerebellopontine angle associated with "SUNCT" syndrome. Cephalalgia 1994;14:301-302.

4. Lim EC, Teoh HL. Headache - it's more than meets the eye: orbital lesion masquerading as SUNCT. Cephalalgia 2003;23:558-560.

5. De Benedittis G. SUNCT syndrome associated with cavernous angioma of the brain stem Cephalalgia 1996;16:503-506.
6. Pareja JA, Sjaastad O. SUNCT syndrome: a clinical review. Headache 1997;37:195-202.

7. Goadsby PJ, Lipton RB. Review of paroxysmal hemicranias, SUNCT syndrome and other short-lasting headaches with autonomic feature, including new cases. Brain 1997;120:193-209.

8. Trucco M, Mainardi F, Maggioni F, Badino R, Zanchin G. Chronic paroxysmal hemicrania, hemicrania continua and SUNCT syndrome in association with other pathologies: a review. Cephalalgia 2004;24:173-184.

9. Schwaag S, Frese A, Husstedt IW, Evers S. SUNCT syndrome: the first German case series. Cephalalgia 2003;23:398-400.

10. Hunt $\mathrm{CH}$, Dodick DW, Bosch EP. SUNCT responsive to gabapentin. Headache. 2002;42:525-526.

11. Graff-Radford SB. SUNCT syndrome responsive to gabapentin (Neurontin). Cephalalgia 2000;20:515-517.

12. Porta-Etessam J, Martinez-Salio A, Berbel A, Benito-Leon J. Gabapentin (neuronetin) in the treatment of SUNCT syndrome. Cephalalgia. 2002;22:249-250.

13. Piovesan EJ, Siow C, Kowacs PA, Werneck LC. Influence of lamotrigine over the SUNCT syndrome: one patient follow-up for two years. Arq Neuropsiquiatr 2003;61:691-694.

14. Chakravarty A, Mukherjee A. SUNCT syndrome responsive to lamotrigine: documentation of the first Indian case. Cephalalgia 2003;23:474-475.

15. Gutierrez-Garcia JM. SUNCT syndrome responsive to lamotrigine. Headache 2002;42:823-825.

16. D'Andrea G, Granella F, Ghiotto N, Nappi G. Lamotrigine in the treatment of SUNCT syndrome. Neurology 2001;57:1723-1725.

17. Leone M, Rigamonti A, Usai S, Damico D, Grazzi L, Bussone G. Two new SUNCT cases responsive to lamotrigine. Cephalalgia 2000;20:845-847.

18. Rossi P, Cesarino F, Faroni J, Malpezzi MG, Sandrini G, Nappi G. SUNCT syndrome successfully treated with topiramate: case reports. Cephalalgia 2003;23:998-1000.

19. Matharu MS, Boes CJ, Goadsby PJ. SUNCT syndrome: prolonged attacks, refractoriness and response to topiramate. Neurology 2002;58:1307.

20. The international Classification of Headache diseases, $2^{\text {nd }} e d$. Cephalalgia 2004;24:(suppl 1).

21. P a reja JA, Shen JM, Kruszewski P, Caballero V, Pamo M, Sjaastad O. SUNCT syndrome: duration, frequency, and temporal distribution of attacks. Headache 1996;36:161-165.

22. Sprenger T, Valet M, Hammes M, et al. Hypothalamic activation in trigeminal autonomic cephalgia: functional imaging of an atypical case. Cephalalgia. 2004;24:753-757.

23. May A, Bahra A, Buchel C, Turner R, Goadsby PJ. Functional magnetic resonance imaging in spontaneous attacks of SUNCT: short-lasting neuralgiform headache with conjunctival injection and tearing. Ann Neurol 1999;46:791-794.

24. Canadillas-Hidalgo FM. The safety and tolerability profile of gabapentin in optimal doses. Rev Neurol 2004;39:371-380.

25. Elwes RD, Binnie CD. Clinical pharmacokinetics of newer antiepileptic drugs. Lamotrigine, vigabatrin, gabapentin and oxcarbazepine. Clin Pharmacokinet 1996;30:403-415.

26. Lain AH, Caminero AB, Pareja JA. SUNCT syndrome; absence of refractory periods and modulation of attack duration by lengthening of the trigger stimuli. Cephalalgia 2000;20:671-673. 